\title{
The teams' formation in sport aerobics on the basis of application of multidimensional analysis methods
}

\author{
Kozina Zh.L. ${ }^{1}$, Shepelenko T.V. ${ }^{2}$, Cieślicka M. ${ }^{3}$, Prusik K. ${ }^{4}$, Muszkieta R. ${ }^{5}$, Osiptsov A.V. ${ }^{6}$, Kostiukevych V.M. ${ }^{7}$, \\ Bazilyuk T.A. ${ }^{8}$, Sobko I.N. ${ }^{9}$, Ryepko O.A. ${ }^{1}$, Polishchuk S.B. ${ }^{1}$, Ilnickaya A.S. ${ }^{1}$ \\ ${ }^{1}$ H.S. Skovoroda Kharkiv National Pedagogical University, Ukraine \\ ${ }^{2}$ Ukrainian State University of Railway Transport, Ukraine \\ ${ }^{3}$ Kazimierz Wielki University in Bydgoszcz, Poland \\ ${ }^{4}$ Gdansk University of Physical Education and Sport, Poland \\ ${ }^{5}$ Nicolaus Copernicus University in Torun, Poland \\ ${ }^{6}$ Mariupol State University, Ukraine \\ ${ }^{7}$ Mykhailo Kotsyubynskyi Vinnitsa State Pedagogical University, Ukraine \\ ${ }^{8}$ Kiev National University of Technology and Design, Ukraine \\ ${ }^{9}$ Kharkov National Economic University, Ukraine
}

\begin{abstract}
Purpose: $\quad$ The purpose of the research is to develop the principles of team's formation in sport aerobics with application of factorial and cluster analysis' methods.

Material: $\quad$ in a research girls $(n=24)$ from the sport aerobics national team (Kharkiv, Ukraine) participated. The athletes were given full medical examination by determination of functional condition of an organism (arterial blood pressure, indicators of a variability of the rhythm of the heart, treadbahn testing), a psycho-physiological condition (time's determination of simple and complex reaction). It was defined physical development and physical fitness and vestibular stability.

Results: $\quad$ The mathematical and visual models of each group of athletes were developed. The cluster analysis permitted selection of 8 groups of girls. The athletes of each group can incorporate with each other in teams for different competitive categories. The each group of athletes should select appropriate programs according to the features of their personal factorial structure of fitness. The general recommendations about selection of programs' story lines for athletes of each group are developed.

Conclusions: The possibilities of athletes' groups formation (in pairs, in trio, in five) for mixed performances are revealed. It is determined that it is possible to select athletes with similar qualities (representatives of one cluster) and with different qualities (representatives of different clusters) for mixed performances.

Keywords: personal, algorithm, aerobics, cluster, analysis.
\end{abstract}

\section{Introduction}

The sport aerobics contains complex, coordination and intensive motor actions. These motor actions include elements of acrobatics, artistic and rhythmic gymnastics. In the course of the training the large arsenal of motor skills with the high coordination exactitude and complexity are formed. Other distinctive feature of sport aerobics is development of strength opportunities: dynamic, static, explosive strength, high-speed and strength endurance. One more feature of sport aerobics is a specificity of competitive activity. The physical activity in sports aerobics is characterized by complex coordination exercises. The exercises are carried out in a zone of the submaximal power in the high-speed and strength, anaerobic and glycolytic mode. The sport aerobics assumes limited mobilization of cardiovascular system's functions at high economical efficiency of power supply mechanisms.

Hu C. F. et al. [1] point that the main sense of aerobics consists in manifestation of beauty of art and the motor action. The aerobics gives the chance to enjoy the beauty of motor compositions.

Jiang G. P. et al. [2] investigated jumps with obstacles in sport aerobics. The authors have determined that

\footnotetext{
(C) Kozina Zh.L., Shepelenko T.V., Cieślicka M., Prusik K., Muszkieta R., Osiptsov A.V., Kostiukevych V.M.,

Bazilyuk T.A., Sobko I.N., Ryepko O.A., Polishchuk S.B.

IInickaya A.S., 2017
}

doi:10.15561/20755279.2017.0603 in a phase of take-off there are two peak phases of manifestation of the maximum strength of a hip and a shin. The peak phase of hip muscles' tension is appeared in a preparatory phase of a jump, and of shin muscles' tension is appeared in a take-off phase. In phase of action in the air the various segments of a body exert various impacts on the effect of the turn. In a landing phase the maximum rotary moment of a coax is much more, than at other joints. The author recommends using the obtained data in training technology of jumps in aerobics.

Li L. [3] offered to use the interactive technologies for learning efficiency's increasing in sport aerobics. The offered technologies promote the development of motors system's visualization in aerobics. It is permitted to realize interactive actions between teachers and pupils. The technology offered by the author represents a new method of the built-in computer system in sports training.

In earlier researches Liu C. S. [4] has offered to use the similar computer network technologies in evaluation of sports competitions.

Nehra N. K. [5] analyzed the reasons and precautionary measures concerning athletic injuries in sport aerobics. The author points that the irrational motor actions, nonstandard platforms and unreasonable methods of training lead to injuries. The muscular and copular deformations, injuries of an ankle joint and knee joint are the most often observed injuries. Injuries of hip muscles are the most often observed. The author also points that insufficient 
warm-up is the main reason of sports injuries.

Nunez R. A. et al. [6] revealed that the most often observed injuries are injuries of limbs. The author points that scientific justification in this sport isn't enough. The large amount of researches devoted to sport aspect of aerobics is concentrated in Spain.

Qiu Q. E. et al. [7] have conducted pilot study of mechanical properties of single materials of sports footwear applied in aerobics. The antiskid properties of Reebok and Huakang footwear were also investigated. The mechanical effect of sports footwear for aerobics was estimated.

Wang X. [8] revealed efficiency of daily trainings in sport aerobics.

Wang Z. C. et al. [9] analyzed the sequence of training of complex motor actions in sport aerobics. The authors revealed interrelation between quality of motor action and physical qualities. The authors determined the consequences of principles of motor skills' transfer for training the complex motor actions. The authors point that the consequences of training the complex motor actions could influence on effects of training. It is revealed that high physical qualities could be useful for fulfillment of complex motor actions. The pupils with high physical qualities could cope better with difficulties in motor actions training. Moreover, they study quickly the combination of motor actions with similar structures or general elements. The teachers of aerobics have to find the reasonable consequences of different complex motor actions' training.

$\mathrm{Wu} \mathrm{T}$. [10] offered the dynamic hierarchical mode in training process and in creation of compositions in sport aerobics.

$\mathrm{Xu}$ W. J. [11] offered the model of training technique of motor actions in sport aerobics based on biomechanics of the human. The technique combines the theory of aerobics training with biomechanical methods of research. The technique is based on the analysis of biomechanical parameters of rotation angle in 720 degrees for athletes. The author revealed the irrational technique during a full course of athletes' actions. The ways of efficient increasing of athletes' training which provide theoretical basis for rational technique's training in sports aerobics are offered.

Yang H. et al. [12] carried out the kinematic analysis of motor actions in sport aerobics. The authors revealed that the structure of skills and key moments of motor action are evidence-based criteria. Such criteria could be used in diagnostics of motility level and selection of talented athletes in elite sport aerobics.

Huang W. Y. et al. [13] ] studied athletes' heart rate variability in aerobics with use of the telemetric monitor of heart rate continuous registration (Polar RS800). The conclusion was drawn that athletes' age, professional level, heart beats rate and gender influence on the variability of heart rate.

Li L. et al. [14] developed the theory of application of musical work digital editing methods in sport aerobics. The author offers a technique of carrying out a preliminary research of digital technologies used in creation of musical work in sport aerobics.

Luo M. F. et al. [15] noticed that sport aerobics has a certain charm and has a certain spiritual values. The authors interpret value orientation of aerobics for creation the bases of deep understanding of its problems. It will permit creating premises for external manifestation of its intrinsic values.

Zhao J. J. et al. [16] pointed out that scientific and reasonable methods of training promote innovations and the development of complex coordination motor actions.

Other researches studied important aspects of athletes' training: mastering of physical fitness [17]; relocation in dancing games [18]; motivation of success achievement $[19,20]$; biomechanical parameters of jumps [21]; mastering of physiological indicators [22]. The authors also considered approaches to optimization of physical activities [23, 24]; didactic bases of training [25, 26]; choice of appropriate tests and pedagogical monitoring $[27,28]$; periodization of training process $[29,30]$ and competitive activity [31, 32]; factors of athletes' success $[33,34]$ and choice of optimized motor action's parameters $[35,36]$.

Nowadays there is insufficiency of theoretical and methodical bases' development of training process' formation in sport aerobics. It is connected to many factors: 1 - sport aerobics is rather young sport; 2 - the aerobics is considered in literature as means of health improvement for people of different age groups. In the modern literature there are a lot of researches devoted to problems of training process' formation in sport aerobics.

Thus, there are problems in training process in sporting aerobics. The greatest attention is paid to physical training of athletes, problems of traumatism and rehabilitation after injuries, to the analysis of biomechanical structure of different motor actions, using of interactive technologies. However the problem of individual approach and teams' formation for group performances in different competitive categories is not practically investigated. Thus, in the modern sport aerobics the principles of athletes' division according to groups for teams' formation are only descriptive. They do not consider the quantitative models and the principles of mathematical and statistical modeling.

The purpose of the research is to develop the principles of teams' formation in sport aerobics on the basis of application of cluster and factorial analysis.

\section{Material and methods}

Participants. The athletes (girls, $\mathrm{n}=24$ ) of the national team and reserve team of sport aerobics (Kharkiv, Ukraine) participated in a research.

Organization of a research. It were used: methods of determination of functional condition of athletes' organism (arterial blood pressure, indicators of variability of the rhythm of the heart [13], treadbahn testing), psychophysiological methods of a research (time determination of simple and complex reaction); methods of physical development and physical fitness' determination; method 
of vestibular stability's determination; simulation method; method of mathematical statistics.

For the analysis of vegetative regulation of heart activity was used a variability of the rhythm of the heart. The record of a signal was carried out on the portable cardiographic equipment «Cardiolab +», (Computer electrocardiograph «Cardiotest» permits to register 12 channels standard ECG, ECG in the lead system by Neb and Frank. For the indicators' analysis is used Dialog box «Complex» Dialog box «Lens» http://www.dx-sys.com. ua/en/products/). The monitor of continuous registration of heart rate model «Polar» with the appropriate software was also used. The record was registered during 5 minutes in a lying position after 5-minute rest.

The subsequent processing of cardiointervals permitted to define a row of statistical characteristics of variability of the rhythm of the heart [13, 37]:

As indicators of heart beats rate we found:

1. Mo (mode of RR-intervals' duration) the most frequent interval between teeth RR (sec.);

2. AMo (amplitude of mode of duration of RRintervals) - percentage of intervals' quantity (the most frequent) to the total quantity of the measured intervals (in our case we used 50 RR-intervals) (\%);

3. $\Delta \mathrm{x}-$ variation range of RR-intervals' duration: there is difference between the highest and the least value of RR-intervals (sec.);

4. Index of tension (conv. un) of regulatory mechanisms (IT) we found by formula:

$\mathrm{IT}=\mathrm{AMo} / 2 \mathrm{Mo} \bullet \Delta \mathrm{x} \quad(1)$,

Where $\Delta \mathrm{x}-$ is the value of variation range of RRintervals' duration (sec.);

Mo - mode of RR-intervals' duration (sec.);

AMo - amplitude of mode of duration of RR-intervals $(\%)$.

In the analysis of heart rate indicators we were guided by the fact that indicators of a heart rate reflect a different contribution of sympathetic and parasympathetic branches of the autonomic nervous system to the process of heart activity regulation. The mode of RR-intervals' duration (Mo) indicates resultant effect of regulatory influences. It reflects the steadiest functioning level in these conditions. The variation range reflects the range of possible deviations option of casual process. It is defined expression of breathing vibration of heart rate. Therefore this indicator is considered as activity indicator of closed-loop control. The amplitude of mode of duration of RR-intervals (AMo) permits to judge about activity of closed-loop control. Thus, increase of AMo duration of RR-intervals and IT witness about tonus increase of sympathetic branch of the autonomic nervous system. Increasing of variation range of RR-intervals' duration witnesses about increase of parasympathetic branch influence of the autonomic nervous system [13, 37].

Our research carried out the testing to define the time of simple and complex reactions to sound and visual stimuli. Time of complex reaction was determined by testing with feedback. Time of the latent period of reaction, an average quadratic deviation, and quantity of mistakes, time of the minimum exposition and time of reach the minimum exposition were defined by time definition of complex visual and motor reaction with feedback [38].

The strength and mobility of nervous system were determined by following: 1) higher strength of a nervous system is provoked by less quantity of mistakes in a submode of complex visual and motor reaction with feedback; 2) higher mobility of a nervous system is provoked by less time in a mode of complex visual and motor reaction with feedback [38].

The vestibular stability was determined with the help of Barany mechanical chair. Rotation of chair was ensured by hand during $20 \mathrm{sec}$ at speed of 2 r.p.sec ${ }^{-1}$. After every $2 \mathrm{sec}$. we registered heart beats rate (HBR) with the help of photoelement equipment. HBR was also registered after rotation during $10 \mathrm{sec}$, after every 2 sec. Increase of HBR before and after rotation was considered as proper reaction to rotation. It is activation of sympathetic branch of autonomic nervous system. Decreasing of HBR before and after rotation was considered as inappropriate reaction to rotation. It is activation of parasympathetic branch of autonomic nervous system (motion sickness). In case of data analysis the HBR indicators on the $2^{\text {nd }}$ sec after the beginning of rotation were selected. The indicators after rotation were also selected [37].

Simulation method. In our research the athletes' models with different structure fitness features were created. The 2 types of models were developed: mathematical and visual. The mathematical models were created based on results of factorial and cluster analysis of personal structure of athletes' fitness. These models were also displayed graphically. The visual models were developed by means of MakeHuman software.

Statistic analysis. Digital material was processed by means of traditional methods of mathematical statistics. The arithmetic average value $\mathrm{X}$, an average quadratic deviation of S (a standard deviation) was determined by each index. The factorial and cluster analysis of testing indicators were also carried out. The obtained data processed by means of Excel and SPSS software.

\section{Results.}

The personal factorial models of athletes (girls) structure fitness were analyzed. The optimum alternative of athletes division on groups for teams' formation is also analyzed. Factorial analysis permitted selection of 4 factors in structure of girls' fitness: «Parasympathicotonia», «Mobility of nervous system», «Strength», «Motor timing». The personal factorial structure of fitness was revealed for each girl. The cluster analysis was carried out for determination the optimum alternative of athletes' selection to the team.

In hierarchical cluster analysis every particular item (athlete) forms firstly the separate cluster. On each stage two the closest clusters incorporate in one cluster. Firstly athletes with the closest analyzable indicators incorporate. Then athletes, similar to them on analyzable indicators join the formed couples. Thus there appear groups of athletes which can be considered as the most similar in 
the fitness structure. Stages of incorporation to clusters are provided in table 1 .

It is possible to notice that the cluster structure of female athletes is more complex on comparing with male athletes. It can be also connected with big variety of types and styles of sport activities at female athletes. The female athletes have not accurately expressed cluster groups, there are intermediate variants. We will consider the formed clusters (groups) of female athletes.

The tab. 1 and fig. 1 provide the following: 1$)$ on the first stage athletes №№ 17 and 24 were incorporated in one cluster.

Thus, these athletes are close by the structure of complex fitness. It needs to be considered in case of: teams' formation for performances in different competitive categories; development of competitive programs; selection of means and methods in training process.

At the following stage of cluster analysis athletes №oㅡ 16 and 23 incorporated. It means that they are close by fitness structure. These athletes differ from the previous incorporated pair (№№ 17 and 24). On the third stage №o 15 and 22, on the fourth - №№ 4 and 8, on the fifth -№№ 1 and 19 incorporated. On the sixth stage № 21 joins to the athletes №№ 4 and 8, incorporating with № 4.

From the sixth stage there is an adding of new athletes in already existing pairs. So, on the seventh stage №№ 20 and 24 incorporate. Such incorporation expands the first pair (№№ 17 and 24). On the eighth stage this group increases by adding № 2 to №17. On the ninth stage № 18 is added to this group, incorporating with № 20 (tab. 1). Thus, the new group of athletes (fig. 1) appears.

On the tenth stage new pair is also formed - №№ 7 and 10. On the eleventh stage - № 6 is added to №№ 1 and 19. On the twelfth stage to №№ 4; 8 and 21 joins № 16. It incorporates with № 4. The group of athletes №oㅡ 16 and 23 extends. As a result the group of athletes №№ $4 ; 8 ; 16 ; 23 ; 21$ appears.

At the following stages № 13 is added to group №oㅡ 1; 19 and 6 (stage 13). Also groups №№ 4; 8; 16; 23; 21 joined. On the fourteenth stage №14 with №13 (tab. 1) are joined them.

On the fifteenth stage the group №№ 1; 19 and 6 extends by adding №№ 7 and 10 .

The following groups are selected:

- №№. 17; 24 and the closest to them on fitness structure №№ $2 ; 18 ; 20$;

- №№ $16 ; 23 ; 4 ; 8 ; 21$

- №№ 13 and 14, the closest on fitness structure to №№ $16 ; 23 ; 4 ; 8 ; 21$

- №№ 15 and 22 and the closest to them on fitness structure №№ 5; 11; 12;

- №№ $1 ; 19 ; 6 ; 7 ; 10$.

Athletes № 9 and № 3 are differ from others. They are added last to the existing groups with big cluster coefficients. They can represent separate clusters.

Thus, it is possible to select several clusters (groups) of athletes.

The optimum quantity of clusters is further defined:

Table 1. The agglomeration order in cluster analysis of psycho-physiological testing indicators of athletes $(n=24)$

\begin{tabular}{|c|c|c|c|}
\hline \multicolumn{3}{|c|}{ Incorporation of athletes in clusters (according to the conventional numbers) } & \multirow{2}{*}{ Coefficients } \\
\hline Stage, № & Cluster 1 & Cluster 2 & \\
\hline 1 & 17 & 24 & ,000 \\
\hline 2 & 16 & 23 & ,000 \\
\hline 3 & 15 & 22 & ,000 \\
\hline 4 & 4 & 8 & 51,158 \\
\hline 5 & 1 & 19 & 54,987 \\
\hline 6 & 4 & 21 & 71,573 \\
\hline 7 & 20 & 24 & 71,865 \\
\hline 8 & 2 & 17 & 85,334 \\
\hline 9 & 18 & 20 & 90,160 \\
\hline 10 & 7 & 10 & 104,215 \\
\hline 11 & 1 & 6 & 111,569 \\
\hline 12 & 4 & 16 & 131,550 \\
\hline 13 & 1 & 13 & 135,590 \\
\hline 14 & 13 & 14 & 169,041 \\
\hline 15 & 7 & 19 & 195,335 \\
\hline 16 & 2 & 12 & 270,578 \\
\hline 17 & 7 & 20 & 299,583 \\
\hline 18 & 3 & 10 & 316,255 \\
\hline 19 & 1 & 9 & 379,291 \\
\hline 20 & 1 & 7 & 381,478 \\
\hline 21 & 5 & 15 & 505,204 \\
\hline 22 & 1 & 2 & 538,594 \\
\hline 23 & 3 & 5 & 1683,142 \\
\hline
\end{tabular}




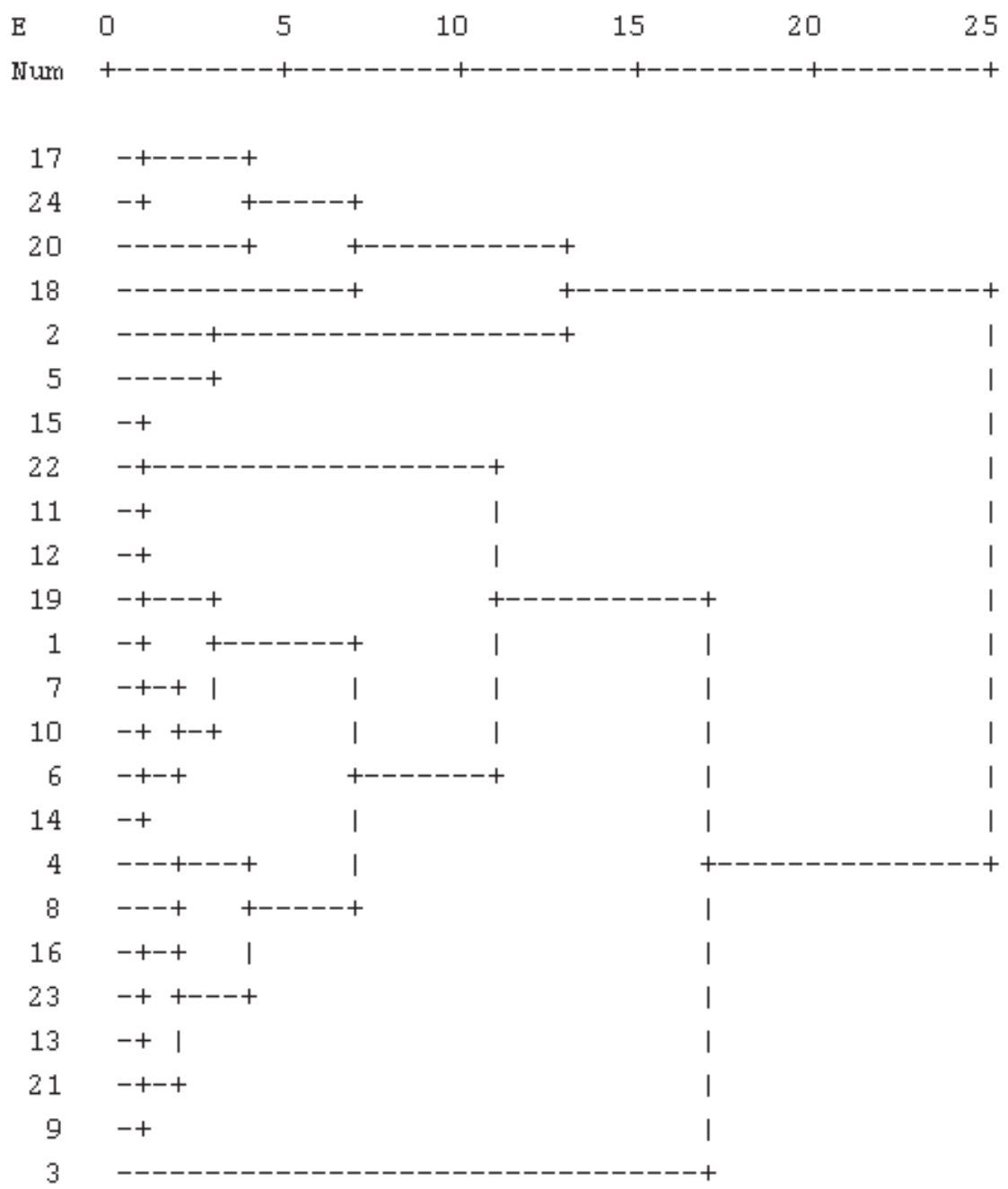

Fig. 1. Dendogram of athletes incorporation in clusters: Rescaled Distanse Cluster Combine - is a scale of the conventional differences between examinees in case of their incorporation; Num - is the conventional number of the examinee.

to subtract from the total quantity of athletes the number of a stage on which cluster coefficients begin to increase non-linearly. In our case there are several such stages (tab. 3): №№ 4; 16;21; 23 stages. Consequently, the optimum quantity of clusters can be:

$24-23=1$ (i.e. all athletes incorporate in one group);

$24-21=3$ (athletes incorporate in 3 groups);

$24-16=8$ (athletes incorporate in 8 groups);

$24-4=20$ (athletes incorporate in 20 groups).

According to the carried-out analysis, we selected incorporation of athletes in 8 groups. Two groups of these athletes will form independent clusters. One group of athletes with the intermediate fitness structure is also selected. The last three groups can be parts of other groups. In this case 5 clusters are formed.

We received 8 clusters or 8 groups of athletes. The figure 1 demonstrates belonging of each athlete to a certain cluster.

Then the analysis of personal factorial fitness' structure of athletes was carried out. The formed groups received characteristics. The visual graphic models of athletes' fitness structure of each group (fig. 2) were developed.

The groups №№ 17; 24; 2 have expressed factor - «Mobility of a nervous system» (fig. 2). It signified that the specified athletes can incorporate with each other in pairs or in trio. They have success in programs which emphasize speed. Such musical works as «Flight of a bumblebee» (N.A. Rimsky-Korsakov), «Joke» (S. Bach), «The Turkish march» (W. Mozart) and others are successful for emphasizing performances story's lines of these athletes.

The athletes №№ 20 and 18 (fig. 2) could be added to the first group as closest on fitness structure for performances in five. They have high expressiveness of factor «Mobility of a nervous system» and factor «Parasympathicotonia» (fig. 2).

In story lines for such athletes it is expedient to select programs with music which combines speed, easiness and lyrics (for example, W. Mozart «The symphony G-major»). 
The following group is athletes №№ $16 ; 23 ; 8 ; 4 ; 21$ (fig. 2). They have most expressed factor «Strength». They have success in programs with accentuation of strength elements: static holdings of partners in different positions. These athletes can play in team with other groups (their role is solo). Such musical works as «Symphony №5» (L. Beethoven) and others will be successful for them.

The athletes №№ 13 and 14 are similar to athletes of this cluster. They form a separate cluster. They have the most expressed factors «Strength» and «Parasympathicotonia» (fig. 2). The programs with the following music will be successful for them: «Sonata № 23», «Appassionato» (L. Beethoven), blues music. The following cluster is formed by athletes №№ 15 and 22. They have highly expressed factor «Strength». These athletes expressed the factor «Motor timing» (fig. 2). They can form team with athletes of the previous clusters (№№ 13; 14 and №№. 16; 23; 8; $16 ; 21)$.

Particular interest is represented by group of athletes with the greatest expressiveness of factor «Parasympathicotonia» №№ 19; 1; 7; 10; 6 (fig. 3) People with prevalence of parasympathetic branch of the autonomic nervous system in a regulation of vegetative balance differ in predilection: to languishing, to asthenia, to emotionality; to dreaminess, to imagination, to contemplation, to figurative perception.
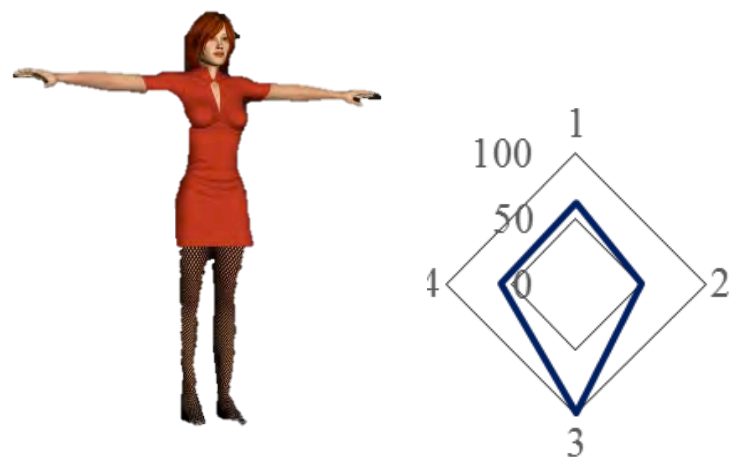

«Mobility of a nervous system»
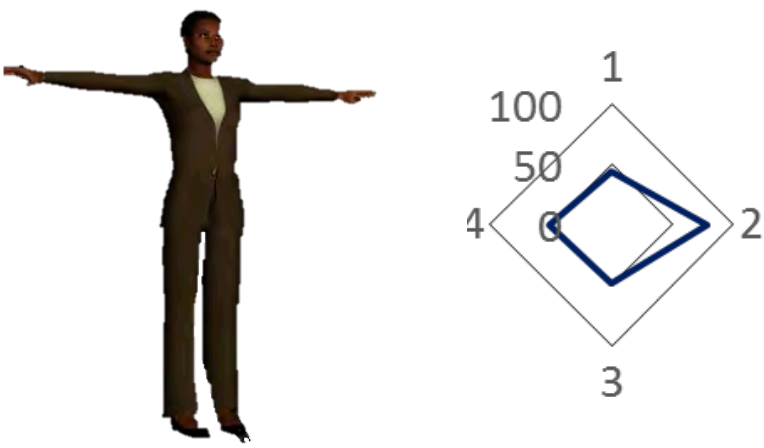

«Strength»
For this group of athletes the high relevance has programs with interesting story line referred to the demonstration of deep feelings and experiences. In their training process the accent should be made on development of visual thinking and ability to demonstrate story structures of the program with the help of various motor actions. The story programs corresponding to the following music works «Seasons» (P. Tchaikovsky), I. Strauss's waltzes, some works F. Chopin are successful for these athletes.

It is necessary to notice that existence of the story line in the performance program in sport aerobics and ability to demonstrate this story line in the motor actions raise a performance of athletes to the new level. It significantly raises level of performance. Such athletes take the leading positions in the world-class championships. Therefore in training of athletes it is important to pay attention to development of visual thinking, ability to demonstrate various images with the help of the motor actions. This ability is the leader at athletes with the most expressed factor «Parasympathicotonia».

The athlete №3 is also selected in a separate cluster (fig. 2). She has approximately equal expression of all factors. She can forms a team with any other clusters and also will be successful in single programs.

Practical work of trainer requires visualization of
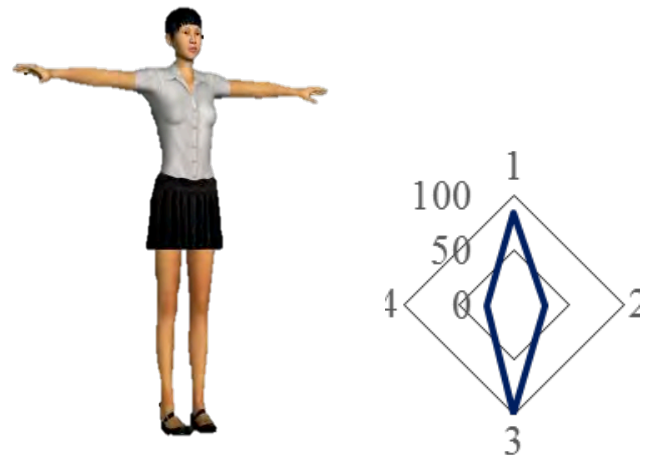

«Mobility of a nervous system» and «Parasympathicotonia»
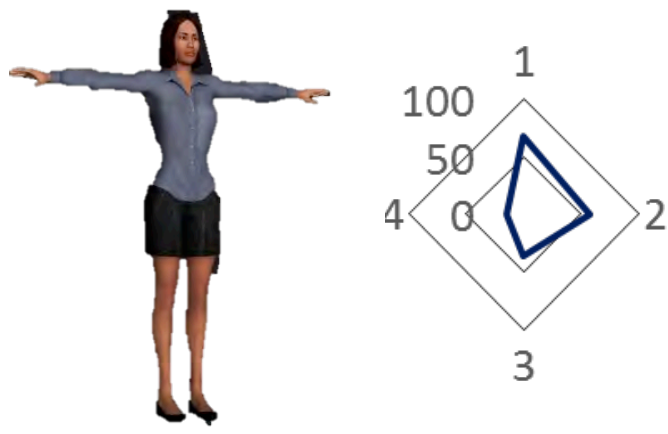

«Strength» and «Parasympathicotonia»

Fig. 2. The examples of individual factorial structure of functional and psycho-physiological opportunities at athletes: results of mathematical and visual 3D-modeling: 1 - Factor «Parasympathicotonia»; 2 - Factor «Strength»; 3 - Factor «Mobility of a nervous system»; 4 - Factor «Sympathicotonia». 

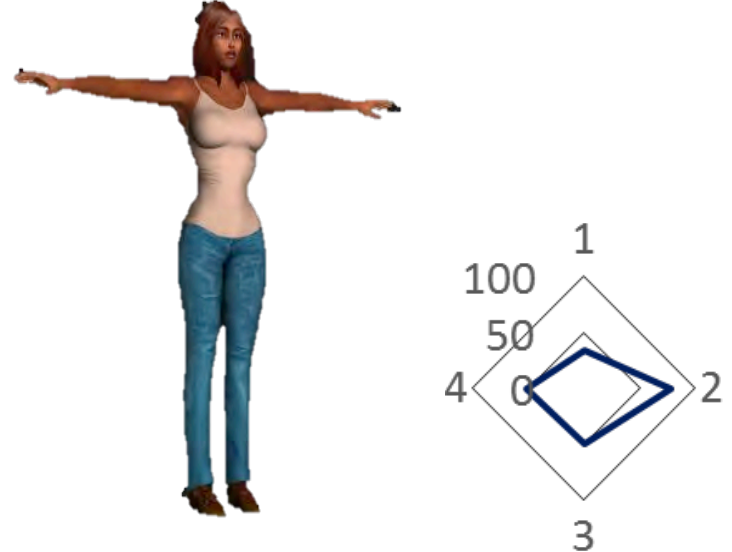

«Strength» and «Motor timing»
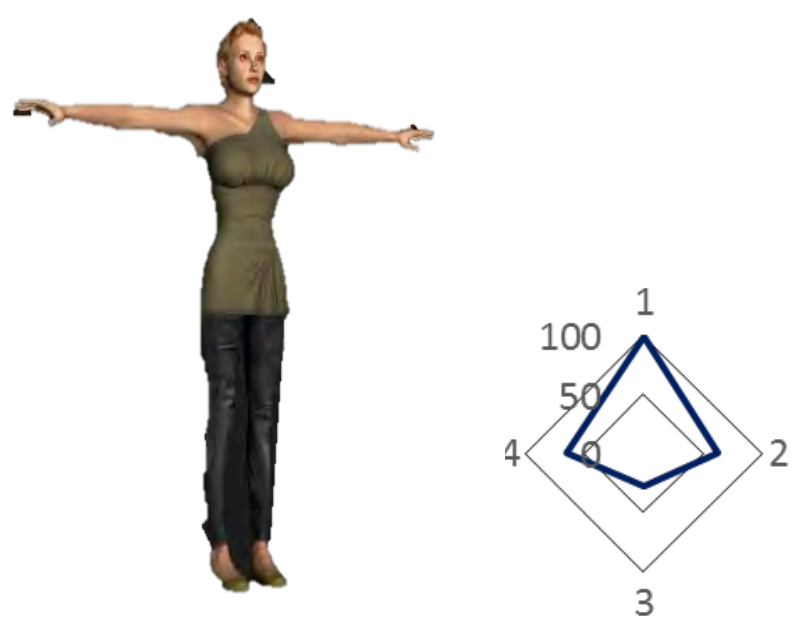

«Parasympathotonia»
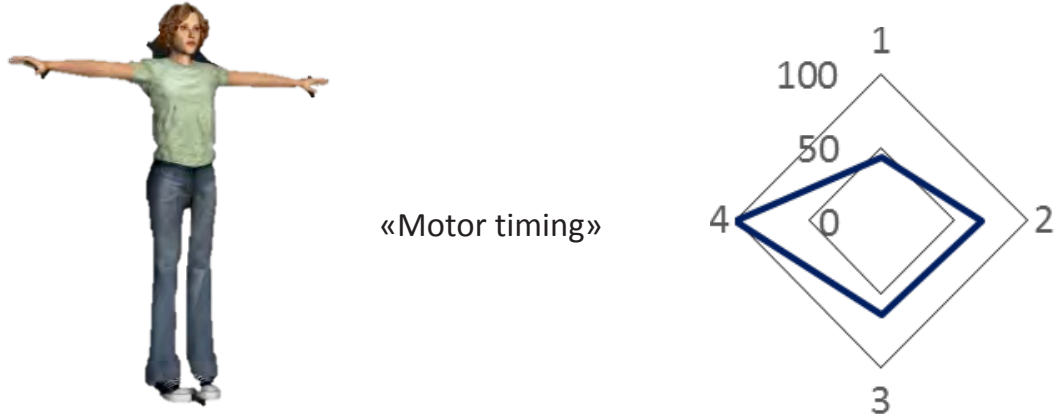

Fig. 3. The examples of individual factorial structure of functional and psycho-physiological opportunities at athletes: results of mathematical and visual 3D-modeling: 1 - Factor «Parasympathicotonia»; 2 - Factor «Strength»; 3 - Factor «Mobility of a nervous system»; 4 - Factor «Sympathicotonia».

external features of athletes with different expression of factors in fitness structure. For athletes types' visualization were created their visual models. Such approach permits creating and visualizing the virtual people.

To create a 3D model of the human (fig. 2), it is necessary to make manipulations and to adjust numerous characteristics of a human body. There are more than 1170 effects which can be changed (age, gender, height, shape of the face and others). In our research these parameters were set according to parameters of athletes representatives of various clusters.

Thus, for definition of groups optimum' alternative for performances in various competitive categories the cluster analysis of testing indicators was carried out. The results of cluster analysis were compared with individual factorial values, athletes' profiles were compiled. On the basis of the obtained data groups of athletes for performances in various competitive categories were formed.

\section{Discussion}

In our research models of athletes with various features of fitness structure were created [39]. The models of 2 types were developed: mathematical [40] and visual. The mathematical models were created on the basis of results of the factorial and cluster analysis of testing indicators and individual factorial structure of athletes' fitness [41, 42]. These models were also displayed graphically. The visual models were developed by means of MakeHuman software.

Such analysis tools were chosen because selection of athletes for incorporation in pairs and groups for performances is a difficult task. It is connected with complexity of sport aerobics.

In our opinion, sport aerobics combines several aspects of motor and psychological activity. The sport aerobics has much in common with dances. Besides, very important components in sport aerobics are artistic and rhythmic gymnastics and acrobatics. The sport aerobics consists of elements of sport and art. The athletes have to have sport and art qualities. The athletes demonstrate these qualities in different ways. That's why the variety of options of differ athletes combinations gives great opportunities for realization of the art and sports ideas.

Nowadays the greatest success in sport aerobics is made by teams which manage to realize any story line in the program. For example, the team from Belgium (trio) in the World Cup in 2014 became the winner of competitions grace to successful selection and demonstration of story 
line. The integrated picture of a certain story was given by music work (music from the ballet «The swan lake» by P.I. Tchaikovsky), suits of participants, character of a performance. The story lines are demonstrated in the best way with the help of dances. Therefore elements of dance are very important for success of performances in sport aerobics. The abilities to demonstrate the necessary story line of the program are especially important.

The dance is one of the most ancient forms of art. The complexes of the special motor actions subordinated to the single story line (hunting, migration, household activities) began to appear. Egyptian images which demonstrate dances are the most popular from the most ancient dancing instructions. Each pose had the value [15]. Thus, presence of the story line is an integral part of the dance.

Nowadays not all teams manage to combine harmonically elements of the competitive program with any story lines which demonstrate with the help of motor actions. The selection of necessary athletes for group formation in different competitive programs also causes difficulties.

In our research was made an attempt to make recommendations about optimum athletes' selection, search of optimum alternative of athletes' incorporation for performances in different competitive categories. The formed groups of athletes were described by leading factors in their personal factorial structure of fitness [39, 42].

Recommendations about selection of the successful story lines were developed for each group of athletes during creation of competitive performances programs. The characteristics of the functional and psychophysiological conditions of athletes were considered.

Such approach gives perspectives of further development of this problem. The advanced study of athletes' classification bases in sport aerobics and selection of competitive programs form backgrounds of this problem.

\section{Conclusions}

1. The cluster analysis permitted selecting 8 groups of athletes. The athletes in each group can incorporate with each other for performances in different competitive categories. Each group of athletes should select appropriate programs according to features of their personal factorial fitness' structure. The general recommendations about selection of programs' story lines for athletes of each group are developed. The visual models of each group athlete's appearance are created.

2. It is revealed that the cluster structure of athletes is rather complex. The athletes have not accurately expressed cluster groups. The groups of athletes received characteristics to the factors which are the most expressed in their fitness structure. The visual graphic models of athletes' fitness structure of each group were also developed.

3. The possibilities of athletes groups forming (pairs, trio, five) for mixed performances are determined. It is revealed that for mixed performances it is possible to select athletes with similar qualities (representatives of one cluster) and with different qualities (representatives of different clusters). The creation principles of athletes' competitive programs for each group are developed.

\section{Acknowledgements}

The research is conducted according to:

- the consolidating plan of research work in the sphere of physical culture and sport for 2011-2015 on a subject 2.4 «Theoretical and methodical bases of individualization in physical training and sport» (№ of the state registration 0112U002001);

- the research work of Ministry of Education and Science of Ukraine for 2013-2014. «Theoretical and methodical bases of application the information, pedagogical and medical-biological technologies for formation of healthy lifestyle» (№ of the state registration 0113U002003);

- the research work of Ministry of Education and Science of Ukraine for 2015-2016. «Theoretical and methodical bases of means application the information, pedagogical, medical-biological orientation for motor and spiritual development and formation of healthy lifestyle» (№ of the state registration 0115U004036).

- the research work of Ministry of Education and Science of Ukraine for 2017-2018. «Theoretical and methodical bases of application of information, medicalbiological and pedagogical technologies for realization of individual physical, intellectual and spiritual potential and formation of healthy lifestyle» (№ of the state registration 0117U000650).

\section{Conflict of interests}

The authors state that there is no conflict of interest. 


\section{References}

1. Hu CF, Xiang Y. Analysis the Relationship of System. Theory and Aesthetics of the Aerobics, 2013;45:101-104.

2. Jiang G, Ji Z, Li X, Guo L. Biomechanical Analysis on Free Falls and Straddle Jump to Push up Difficulty Elements in Sports Aerobics. 9th China National Convention on Sport Science Location: Shanghai; 2012. P. 114-7.

3. Li A. An Analysis of Physiological and Psychological Rehabilitation from Injuries of Sport Aerobics Athletes. Advances in Education Research. 2014;63:206-209.

4. Liu CS. Research on Application of Computer Network Technology in Sports Competition Evaluation. Advances in Intelligent Systems Research. 2012;19:842-4.

5. Nehra NK. Causes and Precautions of Sports Injuries in Competitive Aerobics. Common Development of Sports and Modern Society. 2014;2:49-52.

6. Nunez RA, Gutierrez-Sanchez A, Santana MV. Aerobic gymnastics injuries. Review article. Revista Internacional De Medicina. 2013;13(49):183-99.

7. Qiu QE, Hu QL, Gu YD, Liu GP. Experimental Study on Mechanical Properties of Sole materials of Aerobics sports shoes. Advanced Materials Research. 2012;3: 77-9.

8. Wang X. Study on Daily Training Method of Competitive Aerobics. Advances in Education Research. 2013;38:231-4.

9. Wang Z, Wang XT, Qi ZC. Study on the Teaching Sequence of Ladies' Competitive Aerobics Level III Difficult Movements. Lecture Notes in Management Science. 2012;6:94-98.

10.Wu T. The experimental research on Dynamic hierarchical mode. Information Technology and Industrial Engineering, 2014;1(2):1041-8.

11.Xu WJ. Competitive aerobics training method model based on human biomechanics. Transactions on Information and Communication Technologies, 2014;1(2):1041-8.

12. Yang H, Zheng SB. Kinematic Analysis of Wensen Pushups in Sport Aerobics. Transactions on Information and Communication Technologies, 2012;1(2):112-5.

13.Huang WY, Zhang JA, Liu XX, Yang NE. Factors to Influence HRV of Aerobics Athletes under Increasing Load. 21st PanAsian Congress of Sports and Physical Education Location: Jiangxi Normal Univ, Nanchang; 2010. P. 49-52.

14.Li L, Peng QY, Liu XW. Application Theory of Digital Editing Techniques in the Music Cremation of Aerobic Dancing. Proceedings of the 8th International Symposium on Computer Science in Sport, 2011. P. 343-347.

15.Luo MF, Xu GG. Research on the Spiritual Values of the Charm of Aerobics Sport. Second international conference on education and sports education, 2011. P. 113-116.

16.Zhao JJ, Gao YM. A Research on the Difficulty Movements Training of Competitive Aerobics in Colleges. Second international conference on education and sports education, 2011. P. 209-211.

17.Mayorga-Vega D, Montoro-Escano J, Merino-Marban R, Viciana J. Effects of a physical education-based programme on health-related physical fitness and its maintenance in high school students: A cluster-randomized controlled trial. European Physical Education Review. 2016;22(2):243-59.

18.Nyberg G, Meckbach J. Exergames "as a teacher' of movement education: exploring knowing in moving when playing dance games in physical education. Physical Education and Sport Pedagogy. 2017;22(1):1-14.

19.Chen H, Sun HC, Dai J, Griffin M. Relationships Among Middle School Students' Expectancy Beliefs, Task Values, and Health-Related Fitness Performance. Journal of Teaching in Physical Education. 2017;36(1):40-9.

20.Iermakov SS, Podrigalo LV, Jagiello W. Hand-grip strength as an indicator for predicting the success in martial arts athletes. Archives of Budo. 2016;12:179-86.

21.Giovanelli N, Taboga P, Rejc E, Lazzer S. Effects of strength, explosive and plyometric training on energy cost of running in ultra-endurance athletes. European Journal of Sport Science. 2017;17(7):805-13.

22.Sindiani M, Eliakim A, Segev D, Meckel Y. The effect of two different interval-training programmes on physiological and performance indices. European Journal of Sport Science. 2017;17(7):830-7.

23.Iermakov SS, Arziutov GN, Jagiello W. Quick training of students to judo techniques. Archives of Budo. 2016;12:1524.

24.Balko S, Rous M, Balko I, Hnizdil J, Borysiuk Z. Influence of a 9-week training intervention on the reaction time of fencers aged 15 to 18 years. Physical Activity Review. 2017;5:14654. doi:10.16926/par.2017.05.19

25.Kriventsova I, Iermakov S, Bartik P, Nosko M, Cynarski W. Optimization of students-fencers' tactical training. Ido Movement for Culture-Journal of Martial Arts Anthropology, 2017; 17(3), 21-30. doi:10.14589/ido.17.3.3

26. Arziutov G, Iermakov S, Bartik P, Nosko M, Cynarski WJ. The use of didactic laws in the teaching of the physical elements involved in judo techniques. Ido Movement for CultureJournal of Martial Arts Anthropology, 2016;16(4):21-30. doi:10.14589/ido.16.4.4

27.Khudolii OM, Ivashchenko OV, Iermakov SS, Rumba OG. Computer simulation of Junior gymnasts' training process. Science of Gymnastics Journal, 2016;8(3):215-228.

28.Podrigalo LV, Iermakov SS, Jagiełł W. Special indices of body composition as a criterion of somatic development of martial arts practitioners. Arch Budo Sci Martial Art Extreme Sport 2017; 13: 5-12.

29. Osipov AY, Kudryavtsev MD, Iermakov SS , Jagiello W. Topics of doctoral and postdoctoral dissertations devoted to judo in period 2000-2016 - the overall analysis of works of Russian experts. Archives of Budo, 2017; 13: 1-10.

30.Pivovarnik J. Dual concentration in karate and its use in diagnosis of sport. Physical Activity Review. 2016;4:81-8. doi:10.16926/par.2016.04.10

31.Bliznevsky AA, Kudryavtsev MD, Iermakov SS, Jagiello W. Formation of active-effective attitude of 12-13 years' judo athletes to sports functioning in competition period. Archives of Budo. 2016;12:101-15.

32.Osipov AY, Kudryavtsev MD, Iermakov SS, Jagiello W. Criteria for effective sports selection in judo schools - on example of sportsmanship's progress of young judo athletes in Russian Federation. Archives of Budo, 2017; 13: 179-187.

33. Rosselli AC, Singer JN. Influential Factors that Contribute to Black Golfers' Participation at the Elite-Level. Physical Activity Review. 2017;5:132-45. doi:10.16926/par.2017.05.18

34.Dziadek B, Iskra J, Przednowek K. Running preparation and the final decathlon score in terms of sports career development. Physical Activity Review. 2016;4:115-23. doi:10.16926/par.2016.04.14

35. Wasik J, Gora T. Impact of target selection on front kick kinematics in taekwondo - pilot study. Physical Activity Review. 2016;4:57-61. doi:10.16926/par.2016.04.07

36. Mata JD, Oliver JM, Jagim AR, Jones MT. Sex Differences in Strength and Power Support the Use of a Mixed-Model Approach to Resistance Training Programing. Strength and Conditioning Journal. 2016;38(2):2-7. doi:10.1519/ ssc.0000000000000182

37.Korobeynikov G, Mazmanian K, Korobeynikova L, Jagiełło W. Psychophysiological states and motivation in elite 
judokas. Archives of Budo, 2010;6(3):129-136.

38.Kozina Z, Prusik K, Görner K, Sobko I, Repko O, Bazilyuk T, Kostiukevych V, Goncharenko V, Galan Y, Goncharenko $\mathrm{O}$, Korol S, Korol S. Comparative characteristics of psychophysiological indicators in the representatives of cyclic and game sports. Journal of Physical Education and Sport, 2017;17(2):648 - 655 .

39.Zhanneta K, Irina S, Tatyana B, Olena R, Olena L, Anna I. The applying of the concept of individualization in sport. Journal of Physical Education and Sport. 2015;15(2):172177. doi:10.7752/jpes.2015.02027
40.Kozina ZL, Jagiello Wladyslaw, Jagiello Marina. Determination of sportsmen's individual characteristics with the help of mathematical simulation and methods of multidimensional analysis. Pedagogics, psychology, medicalbiological problems of physical training and sports, 2015; 19(12): 41-50. doi:10.15561/18189172.2015.1207

41.Sobko I. An innovative method of managing the training process of qualified basketball players with hearing impairment. Journal of Physical Education and Sport, 2015;15(4):640-645: doi:10.7752/jpes.2015.04097

42.Kozina ZhL, Prusik Krzysztof, Prusik Katarzyna. The concept of individual approach in sport. Pedagogics, psychology, medical-biological problems of physical training and sports, 2015; 19(3): 28-37. doi:10.15561/18189172.2015.0305

Information about the authors:

Kozina Zh.L.; http://orcid.org/0000-0001-5588-4825; Zhanneta.kozina@gmail.com; H.S. Skovoroda Kharkiv National Pedagogical University; Alchevskyh str. 29, Kharkov, 61002, Ukraine.

Shepelenko T.V.; http://orcid.org/0000-0002-6401-2364; shepelenko_tatyana@ukr.net; Ukrainian State University of Railway Transport; Feuerbach square 7, Kharkov, 61050, Ukraine.

Cieślicka Mirosława; http://orcid.org/0000-0002-0407-2592; cudaki@op.pl; Kazimierz Wielki University in Bydgoszcz; Chodkiewicza str. 30, 85-064 Bydgoszcz, Poland.

Prusik Katarzyna; http://orcid.org/0000-0002-2960-5105; prusik@hot.pl; Gdansk University of Physical Education and Sport; Kazimierza Gorskiego 1, 80-336 Gdansk, Poland

Muszkieta Radosław; http://orcid.org/0000-0001-6057-1583; radek@muszkieta.com; Nicolaus Copernicus University in Torun; Jurija Gagarina 11, 87-100 Toruń, Poland.

Osiptsov A.V.; http://orcid.org/0000-0002-1640-2632; osipcov_andrey@mail.ru; Mariupol State University; Budivelnykiv Ave., 129a, Mariupol, 87500, Ukraine.

Kostiukevych V.M.; http://orcid.org/0000-0002-6215-764X; v.m.kost@mail.ru; Mykhailo Kotsyubynskyi Vinnitsa State Pedagogical University; Ostrozky str. 32, Vinnitsa21100, Ukraine.

Bazilyuk T.A.; http://orcid.org/0000-0002-6244-6302; baziluk@rambler.ru; Kiev National University of Technology and Design; st. Nemirovich-Danchenko, 2, Kiev, 01000, Ukraine.

Sobko I.N.; http://orcid.org/0000-0002-4920-9775; sobko.kh@mail.ru; Kharkov National Economic University; Lenina boulevard 9a, 61001, Kharkov, Ukraine.

Ryepko O.A.; http://orcid.org/0000-0001-6879-6015; chigiki.ua@mail.ru; H.S. Skovoroda Kharkiv National Pedagogical University; Altshevskih str. 29, Kharkov, 61002, Ukraine.

Polishchuk S.B.; http://orcid.org/0000-0001-8275-4567; staspolischuk@mail.ru; H.S. Skovoroda Kharkiv National Pedagogical University; Altshevskih str. 29, Kharkov, 61002, Ukraine.

IInickaya A.S.; http://orcid.org/0000-0001-5835-8847; anita487@mail.ru; H.S. Skovoroda Kharkiv National Pedagogical University; Altshevskih str. 29, Kharkov, 61002, Ukraine.

Cite this article as: Kozina ZhL, Shepelenko TV, Cieślicka M, Prusik K, Muszkieta R, Osiptsov AV, Kostiukevych VM, Bazilyuk TA, Sobko IN, Ryepko OA, Polishchuk SB, Ilnickaya AS. The teams' formation in sport aerobics on the basis of application of multidimensional analysis methods. Physical education of students, 2017;21(6):270-279. doi:10.15561/20755279.2017.0603

The electronic version of this article is the complete one and can be found online at: http://www.sportedu.org.ua/index.php/PES/issue/archive

This is an Open Access article distributed under the terms of the Creative Commons Attribution License, which permits unrestricted use, distribution, and reproduction in any medium, provided the original work is properly cited (http://creativecommons.org/licenses/by/4.0/deed.en).

Received: 05.09.2017

Accepted: 26.09.2017; Published: 08.12.2017 